\title{
Research Competencies Mediated by Technologies: A Systematic Review of the Literature in Scopus
}

\author{
Carlos Enrique George-Reyes* 1 and Leonardo David Glasserman-Morales ${ }^{2}$ \\ 1 School of Humanities and Education, Tecnologico de Monterrey, 64849 Monterrey, Mexico; \\ cgeorge@tec.mx \\ 2 School of Humanities and Education, Tecnologico de Monterrey, 64849 Monterrey, Mexico; \\ glasserman@tec.mx \\ * Correspondence: cgeorge@tec.mx
}

Received: date; Accepted: date; Published: date

\begin{abstract}
Cultivating research competencies facilitated by the use of technology in the university is crucial to boost acquisition of knowledge, educational innovation, and successful professional development. The objective of this article is to analyze the evolution and characteristics of scientific production that has had the greatest impact on the momentum of investigative competencies and their articulation within technological scenarios. Applying various selection criteria in the Scopus database, we utilized systematic, bibliometric mapping as a methodological strategy in which 250 articles related to the topic were identified, then analyzed with the semantic analysis software VOSViewer. The results indicate that there is an emerging line of research on the subject since 2016 and point to the underdevelopment of lines that associate research skills with digital literacy, information literacy, digital libraries databases, and the development of critical thinking.
\end{abstract}

Keywords: Research competencies, digital literacy, higher education, bibliometric analysis, educational innovation.

\section{Introduction}

Research to generate knowledge at the university level has become a priority [1], hence, teachers and students must develop critical inquiry skills that allow them to access and reconstruct information and share it as a means to confront successfully the professional demands that currently prevail in the knowledge society. Note that the development of research competencies is not a synonym for the training of scientific researchers, but rather for professionals from the various disciplines who are devoted, qualified, and capable of searching for knowledge, curating bibliographic material, and constructing theoretical solutions for complex problems that arise.

In scientific literature, exploratory studies performed regarding the development of research competencies in the university have been published in the last ten years [2-4]. Many authors [5,6] have agreed that strengthening these types of competencies impacts the academic development of professionals and empowers students to perform activities related to the selection, structuring, and analysis of information for the production and sharing of knowledge.

Conceptually, research competencies are linked to the ability to manage bibliography critically $[7,8]$ and to broaden knowledge, skills, and attitudes. College students must learn to apply research methods and techniques to interpret, argue, and propose alternative solutions to the disciplinary problems that are posed to them in their training [9].

George and Salado [10] propose that research competencies in college include the sets of strategies that function to retrieve bibliography efficiently, develop skills in problem identification, and suggest creative solutions that are theoretically validated. Also, students must learn to generate and update disciplinary knowledge and to promote research as a means of learning [11]. Therefore, 
the development of research competencies must be understood as a process oriented toward strengthening the habit of permanent inquiry, thinking critically, and developing specific research skills $[12,13]$.

It is noteworthy that an increasingly strong bond between the development of research competencies and digital competencies has developed because the use of digital technologies facilitates methodologies to access learning and knowledge [14-17]. Also, the technologies are increasingly an important part of day-to-day educational practice [18-20]. Millard et al. [21] acknowledge that digital competency entails, among other meanings, knowing how to find and be critical of the available information in digital media, as well as use it responsibly in academic life. Therefore, the development of digital competencies alongside research competencies implies not only the effective use of technologies but also skills in managing information. In other words, it is not enough to make a digital device work; it is also necessary to develop intentional processes using digital tools to store, manage, and analyze bibliographical data [22].

Likewise, Márquez et al. [23] point out that to strengthen these competencies, the students must grasp information and communication technologies well and have a complete understanding of digital, bibliographic consultation processes. So, the literature shows that research competencies (RC) are closely linked to digital competencies, and these are crucial for the successful completion of professional programs in higher education. The development of these skills highly impacts international scientific production.

Consequently, in this investigation, the relationship between both competencies (DRC) was examined through a bibliometric analysis using the Scopus database and the VOSViewer software. The methodology followed was the one laid out by López et al. [24], and Pérez and Vladimirovna [25], which suggests performing these types of studies by analyzing titles, keywords, and abstracts of scientific texts. The objective was to characterize scientific production to define the background of the research, its current landscape, and the points of interest for further investigation.

\section{Materials and Methods}

The objective of this study was to perform a quantifiable data analysis of scientific literature that has had the greatest impact on the subject of Digital and Research Competencies (DRC); the source was data stored in the Scopus bibliographic database. We intended to identify the different dimensions and trends in international research in this subject and, thus, have a more certain understanding of the conceptual perspectives of the relationship between the development of research processes and the use of technologies.

To achieve this objective, we performed a systematic mapping of the literature based on the proposed methodology by Petersen et al. [26] and adjusted by García and Ramírez [27]. Many authors have used this methodology $[24,25,28,29]$ and they agree that the following stages must be carried out: 1) definition of the guidance questions, 2) location of scientific production, 3) refinement of identified scientific production, 4) design of the bibliographic database, and 5) analysis of the bibliographic information.

\subsection{Definition of guidance questions}

To begin the systematic mapping, we defined some questions that would help guide the study toward analyzing the evolution and characteristics of scientific production that has had the greatest impact on the development of research competencies and their connection with technological scenarios. Based on this, we formed the following questions:

Q1. What is the distribution of publications per year?

Q2. What has been the diachronic evolution on the link between research competencies and digital competencies?

Q3. What is the distribution of scientific publications per country?

Q4. Which research areas have emerged because of the systematic mapping of the identified literature? 


\subsection{Obtaining scientific production}

As a source of information, Scopus from Elsevier Editorial was selected because it is one of the main international databases of peer-reviewed academic information. It offers an exhaustive summary of the results of extensive world research in multiple scientific fields, and finally, it also allows searches of metadata for the most significant publications in different areas of knowledge [30].

Our searches took place from March through May of 2020 and considered the following criteria for inclusion: 1) temporal restrictions were not imposed, that is, a historical analysis on the researched subject was sought; 2) key terms were identified relevant to the investigation's purpose; 3) the key terms were adjusted to the conceptual criteria of UNESCO's thesaurus; 4) the keywords used were digital competence and digital skills because they were the main approach, higher education as a contextual element, and researcher and investigative process as articulating terms; 5) combined searches were performed with the keywords; 6) the search was narrowed to articles published in scientific journals, and 7) searches were performed using English, Spanish and Portuguese.

After obtaining the first results, the thematic not related to social sciences were eliminated. Also, keywords that approximated other study areas were excluded, and those that were associated with higher education and the use of technology were selected. Finally, conference proceedings and book reviews were excluded to focus the search on peer-reviewed publications. The search operators were assembled in the following query:

( TITLE-ABS-KEY ( digital AND skills) AND TITLE-ABS-KEY ( researchers ) OR TITLE-ABS-KEY ( digital AND process ) ) AND ( LIMIT-TO ( PUBSTAGE, "final")) AND ( LIMIT-TO (DOCTYPE, "ar")) AND (LIMIT-TO ( SUBJAREA, "SOCI") OR LIMIT-TO ( SUBJAREA, "COMP") OR LIMIT-TO ( SUBJAREA, "ARTS")) AND ( LIMIT-TO ( LANGUAGE, "English" ) OR LIMIT-TO ( LANGUAGE, "Spanish") OR LIMIT-TO (LANGUAGE, "Portuguese")) AND (EXCLUDE (SUBJAREA, "BUSI") OR EXCLUDE (SUBJAREA, "MEDI") OR EXCLUDE (SUBJAREA, "ENVI") OR EXCLUDE (SUBJAREA, "HEAL") OR EXCLUDE (SUBJAREA , "PHAR") OR EXCLUDE (SUBJAREA, "ECON") OR EXCLUDE (SUBJAREA, "EART") OR EXCLUDE (SUBJAREA, "MATE" ) OR EXCLUDE ( SUBJAREA, "AGRI") OR EXCLUDE ( SUBJAREA, "BIOC" ) OR EXCLUDE ( SUBJAREA, "ENER" ) OR EXCLUDE (SUBJAREA, "NURS") OR EXCLUDE ( SUBJAREA, "PHYS")) AND (EXCLUDE (EXACTKEYWORD, "Article") OR EXCLUDE ( EXACTKEYWORD , "4-Adolescence" ) OR EXCLUDE ( EXACTKEYWORD , "Digital Game-based Learning" ) OR EXCLUDE ( EXACTKEYWORD , "Digital Games") OR EXCLUDE ( EXACTKEYWORD , "Search Engines" ) OR EXCLUDE ( EXACTKEYWORD, "Young People") OR EXCLUDE ( EXACTKEYWORD，"Children") OR EXCLUDE ( EXACTKEYWORD , "Middle East") OR EXCLUDE ( EXACTKEYWORD , "North Africa" ) OR EXCLUDE ( EXACTKEYWORD , "Arabic Content" ) OR EXCLUDE ( EXACTKEYWORD , "Clinical Competence" ) OR EXCLUDE ( EXACTKEYWORD , "Egypt" ) OR EXCLUDE ( EXACTKEYWORD, "Game Design") OR EXCLUDE ( EXACTKEYWORD , "Health Information Literacy" ))

\subsection{Refinement of the identified scientific production}

As observed in Table 1, at least five refinements were performed on the information using the result selection tools on Scopus, which meant modifying the search query several times. This was done to refine the information source precisely. Finally, the titles and summaries of each of the publications were read to eliminate those that did not fulfill the initial considerations and would lead to false positives.

Table 1. Result of refinement of the search query

\begin{tabular}{cccc}
\hline Refinement & $\begin{array}{c}\text { Number of } \\
\text { documents }\end{array}$ & $\begin{array}{c}\text { Articles in scientific } \\
\text { journals }\end{array}$ & $\begin{array}{c}\text { Documents from } \\
\text { international } \\
\text { conferences }\end{array}$ \\
\hline $\begin{array}{c}\text { First refinement } \\
\text { Second }\end{array}$ & 766 documents & 503 & 263 \\
$\begin{array}{c}\text { refinement } \\
\text { Third refinement }\end{array}$ & 580 documents & 419 & 161 \\
Fourth refinement & 328 documents & 396 & 103 \\
Fifth refinement & 250 documents & 328 & 0 \\
\hline
\end{tabular}




\subsection{Designing the bibliographic database}

After refining the bibliographic search, we constructed the database using Excel software (see Appendix A), pinpointing the following fields: 1) author, 2) working title, 3) year, 4) source data (name of the journal, volume, year, article number, pages, DOI, abstract, keywords, references, editorial), 5) country, 6) language, 7) type of document, and 8) type of access. Finally, we assigned a sequential identifier to each document.

\subsection{Analysis of the bibliographic information}

To perform the analysis of the results, we used the VOSViewer software because it allows the construction of bibliometric networks. It is a practical tool to know the trends of scientific production because it allows the visualization, structuring, and taxonomical grouping of concepts and keywords [25]. Various authors have widely used this tool in the education area [31-35] and, on a smaller scale, to evaluate research activity [36,37].

As a research strategy, bibliometric maps were constructed on a bidimensional plane to locate the relationship between several analysis units and the density of their presence in the addressed subject. For this, the following studies were performed, 1) regarding the information on the number of publications per year and country; 2) regarding the co-occurrence of keywords, and 3) regarding the co-occurrence of titles and abstracts. The co-occurrence studies were performed automatically by the software by calculating the frequency of the keywords, titles, and abstracts. To define the results, we used groupings with a minimum of ten entries, and we refined the items (terms) to cleanse the database of grammatical connectors. Two types of maps were drawn up: 1) item density and 2) cluster density (groups of words). The former was constructed from characteristics of publications such as year, country of origin, and keywords. The cluster density considered data from the titles and abstracts. These maps allowed the visualization of trends related to the subject of research and digital competencies. These trends reflect the impact of a specific term and its relationship to associated investigations [38].

\section{Results}

\subsection{Q1Distribution of publications per year}

The first analysis identified the number of publications per year. It was not limited by a specific time to gather knowledge on the origins of the research topic or its chronological evolution. It is noteworthy that the number of publications has increased over the years; nevertheless, there is a contradiction regarding the postulated Price law [39], in the sense that scientific production has not doubled every ten years. On the contrary, Figure 1 shows that between 1962 and 2011, there were fewer than ten articles published every 12 months.

It is not until 2016 that we observe an increase in the production of articles. In that year, 25 documents were published (10\% of the total number); in 2017, 26 (10.4\%); in 2018, 35 (14\%), and in 2019, 53 (21.2\%). The explanation for this could be that in 2014 an era of internet stability arrived in universities with acceptable connection speeds [40], allowing access to large bibliographic databases. We infer that this fact sparked a link between the competencies that are necessary to participate in scientific research processes with the use of digital technologies. The seeming drop in production observed in 2020 is because, at the time of this document, the year had not ended. 


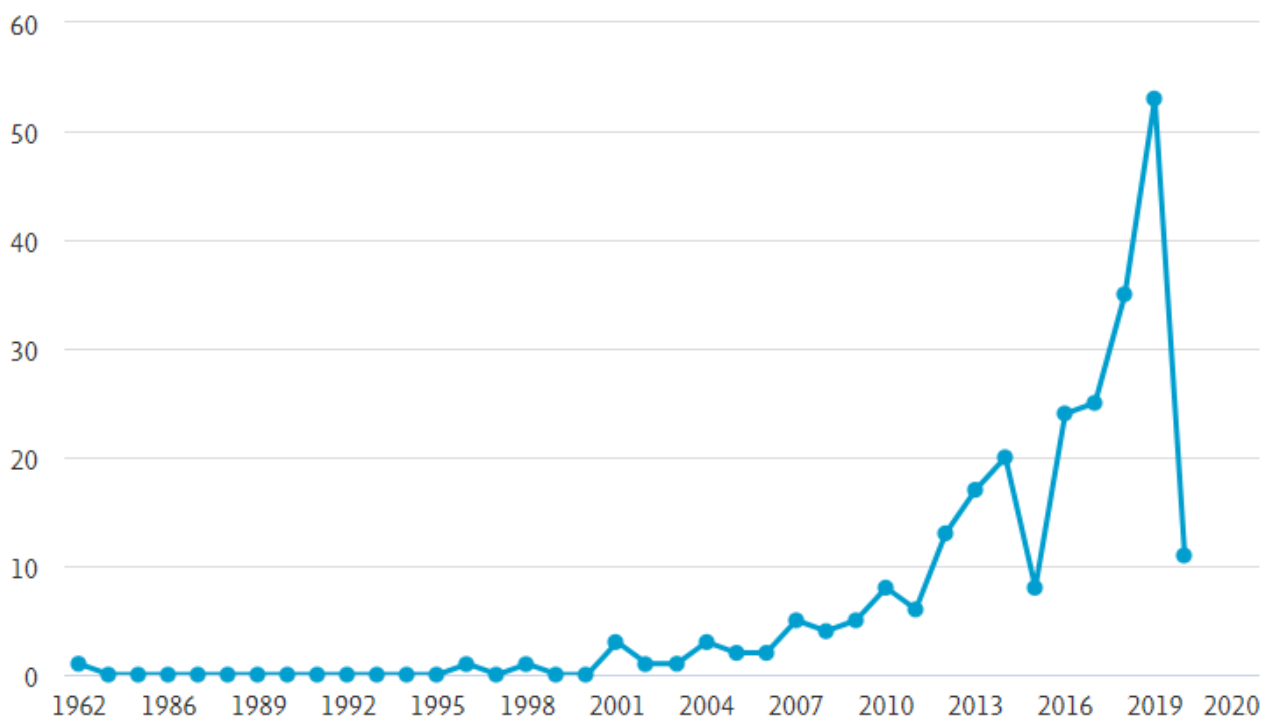

Figure 1. Scientific production by year of publication.

\subsection{Q2 Diachronic evolution between digital competencies and research competencies (DRC)}

Regarding the conceptual evolution of DRCs, between 1962 and 1998, the relationship between research skills and digital approaches was already being described. There were affirmations about the great potential of computers in universities to be a tool to classify, store, and retrieve documents swiftly to meet the growing information requests made by library users [41].

From 2014 on, during the boom and expansion of the digital era, it became apparent that the growth of research data required a much more robust technological infrastructure to provide the storage, preservation, and open access to information demanded [42]. The need to strengthen digital literacy, with a focus on critical skills to search, manage and examine the vast amount of information available online, came to attention [43,44]. It also became important to evaluate the impact of the emerging reading formats based on virtual scenarios [45].

In recent years, the strengthening of DRC can be observed, since it is understood that the handling of data processing skills is essential to young academic researchers, regardless of their disciplinary field [46]. Works like the one produced by Kammerer et al. [47] state that technological developments such as mobile devices and digital assistants are changing how people search for information, acquire knowledge, learn, and create research agendas. In another study, Quyyum and Smith [48] state that the affinity to use digital technologies among more experienced college students has led, in some cases, to changes in research skills such as knowing how to use digital libraries, complement searches with the use of advanced features in specialized databases, and working with keywords.

Based on this analysis, the evolution of DRC as a concept may be located diachronically in three stages. The first one, from 1962 to 2004, came about due to the urgent need of universities to store and categorize large sets of data to preserve scientific literature and expedite its consultation, for both scientists and students. The second one, from 2005 to 2014, occurred because universities began to have an increasingly adequate technologic infrastructure to expand the access to scientific production databases. In this period, digital literacy became a critical training need for functional skills to seek, find, filter, categorize, and use relevant information to achieve educational objectives successfully and meaningfully.

Finally, in the third stage from 2015 to the current day, DRCs result from the demands of an increasingly large and complex informational environment that requires acquiring knowledge about new cognitive mechanisms for finding and using relevant information, making use of digital devices that can be multiconnected to articulated networks, and disseminating knowledge. Research also shows that digital skills now require continuous improvement of research processes where professors play a leading role as mentors who influence the strengthening of digital research competencies in their students [49]. 


\subsection{Q3 Distribution of scientific publications per country}

In Figure 2, we observe that the United States leads the countries with the greatest production on the subject with 85 articles (34\%), followed by the United Kingdom with $42(16.8 \%)$, and Australia with $23(9.2 \%)$. In Iberoamerica, Spain is the country with the most scientific production, with 12 documents published (4.8\%). Among them, the article written by Pérez et al. [50] stands out, where several models of digital literacy were studied in depth under four dimensions, one of them related to critical skills to analyze and understand information that is accessed through technology.

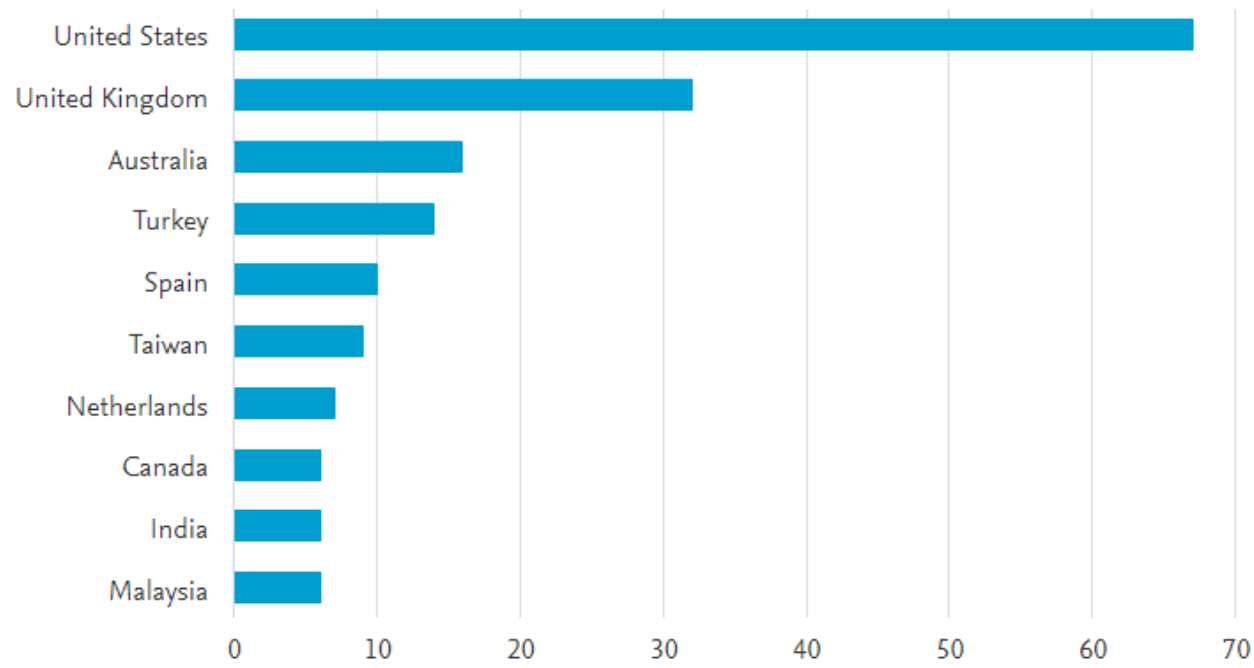

Figure 2. Scientific production per country.

The United States, being the country with the most scientific production, has the largest number of citations (1295), followed by the United Kingdom (709) and Australia (72). However, countries like Taiwan (112 citations, nine documents) and South Africa (152 citations, eight documents) greatly surpass Australia, which is in third place in the number of publications (23). In Iberoamerica, Spain stands alone at the top of the list with 12 published documents and 29 related citations (see Figure 3).

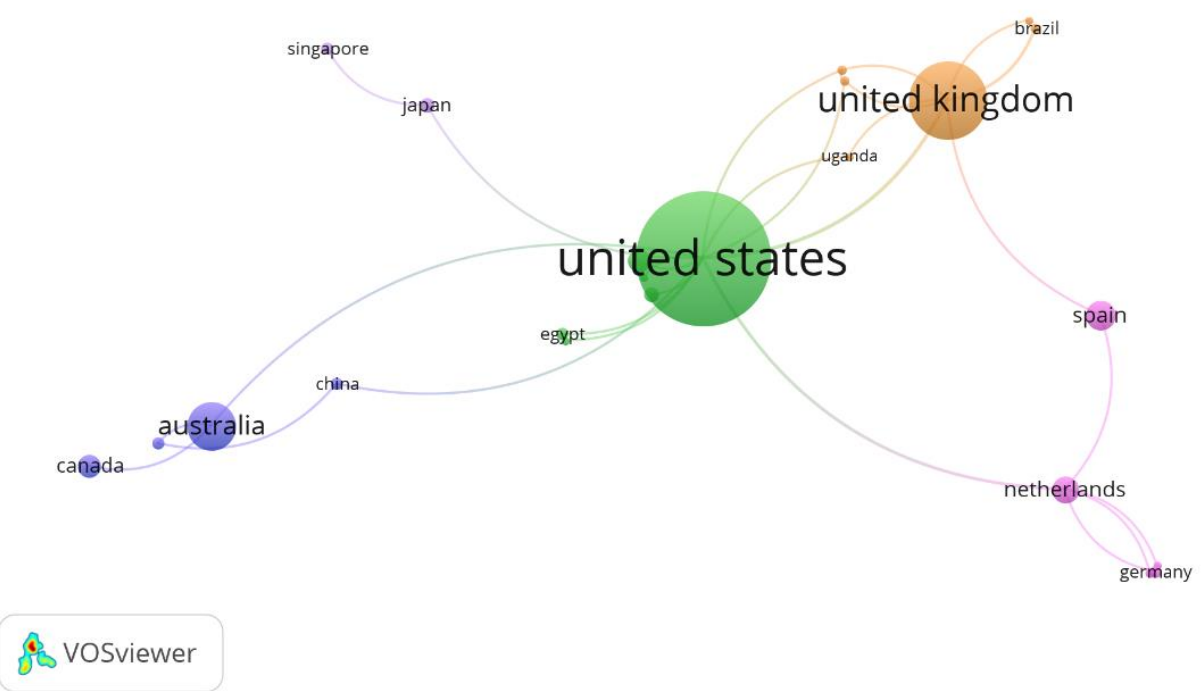

Figure 3. Scientific production per country. 
To identify the emerging lines of research, first, 1,967 keywords belonging to the 250 selected articles were analyzed. With this information, the inference was made as to which are the current trends in the subject. The keywords with the most co-occurrences (the number of times that a term is repeated) are Digital Literacy (23), Research (18), and Informational literacy (17). There also exists a group of co-occurrences linked to the terms Media literacy (10), Digital/Media literacy (10), and New literacies (10). This suggests that, from some authors' point of view, the DRCs are part of several different types of digital literacies (see Table 2).

\begin{tabular}{c|c|c}
\multicolumn{3}{c}{ Table 2. Co-occurrences of Keywords. } \\
Keywords & Co-occurrences & Total link strength \\
\hline Education & 28 & 70 \\
\hline Students & 26 & 91 \\
\hline Digital literacy & 23 & 48 \\
\hline e-learning & 21 & 64 \\
\hline Digital libraries & 19 & 37 \\
\hline Research & 18 & 26 \\
\hline Informational literacy & 17 & 30 \\
\hline Teaching & 17 & 32 \\
\hline Digital divide & 17 & 13 \\
\hline Higher education & 16 & 7 \\
\hline Digital technologies & 16 & 17 \\
\hline Collaboration & 16 & 28 \\
\hline Learning & 16 & 9 \\
\hline Learning systems & 15 & 24 \\
\hline Technology & 14 & 17 \\
\hline Internet & 14 & 11 \\
\hline Educational technology & 14 & 26 \\
\hline Knowledge management & 13 & 9 \\
\hline Professional development & 12 & 22 \\
\hline Information management & 11 & 39 \\
\hline Digital humanities & 11 & 24 \\
\hline Media literacy & 10 & 6 \\
\hline Digital/media literacy & 10 & 31 \\
\hline Digital storage & 10 & \\
\hline New literacies & 10 & 12 \\
\hline Critical thinking & 10 & \\
\hline
\end{tabular}

In Figure 4, the underlying relationships of the co-occurrence of keywords in the selected articles from the Scopus database can be seen. Six clusters or groupings around the subject are observed, the most relevant by the number of words agglomerated are three. The first one, colored blue, is centered on the relationship of digital literacy to education, which, as previously mentioned, is placed as a meta-concept that integrates DRC among its elements. In it, there is a close conceptual link between the terms digital divide, digital literacies, digital literacy, and digital technologies. The second important cluster, colored green, revolves around students and is linked to terms like educational technology, teaching, and, especially, critical thinking, which addresses the need to analyze, organize, evaluate, and process information that people have around them. In the case of education, it means adequately managing the learning processes [51]. 


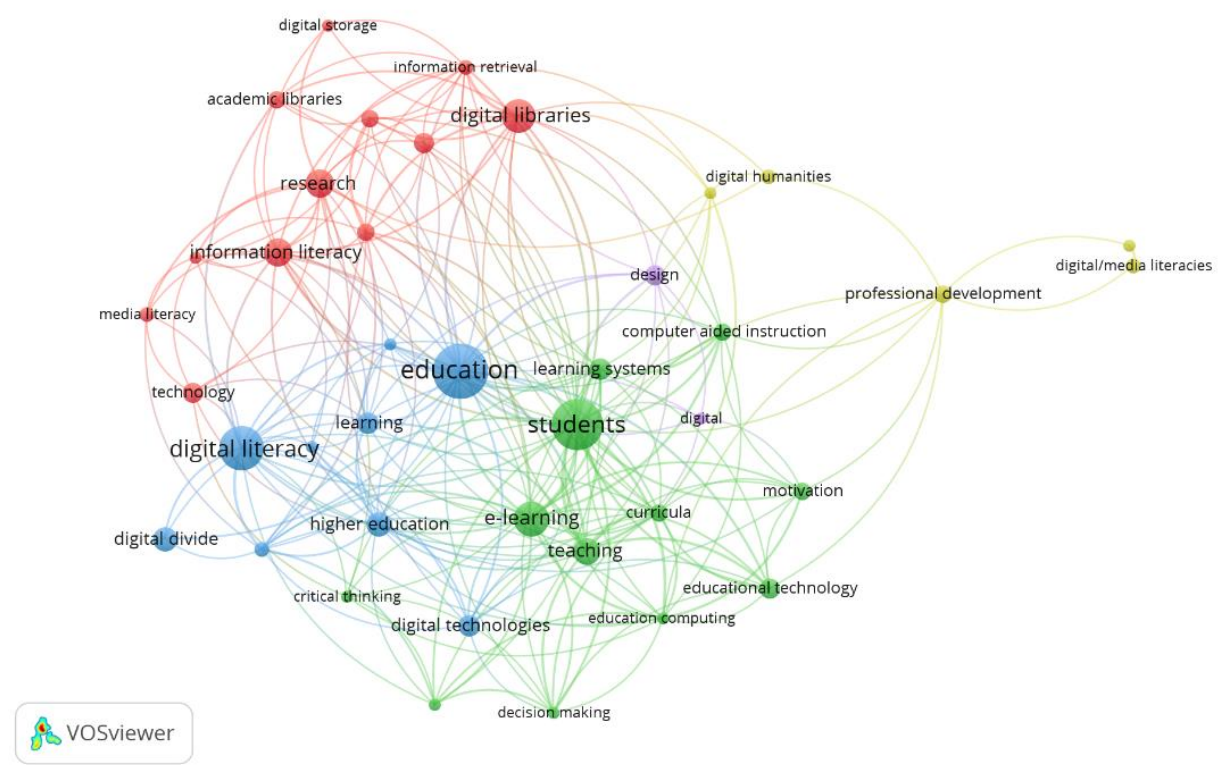

Figure 4. Bibliometric map by keywords.

Finally, the third cluster, colored red, is of greater interest in this investigation, as it is where the articulation of terms such as digital literacy and research can be found. As observed in Figure 3, the network of keywords is intertwined with other contributions found in the articles, like information literacy, learning, digital literacies, technology, and the internet. Something that stands out is the relationship that emerges with the item digital humanities, as shown in Figure 5. It is a concept that seeks to understand the impact that digital technology has on the skill to analyze the large amounts of data that exist in cyberspace, as well as the ability to develop and prepare digital resource databases [52] for accessing, storing, preserving and disseminating large masses of information [53].

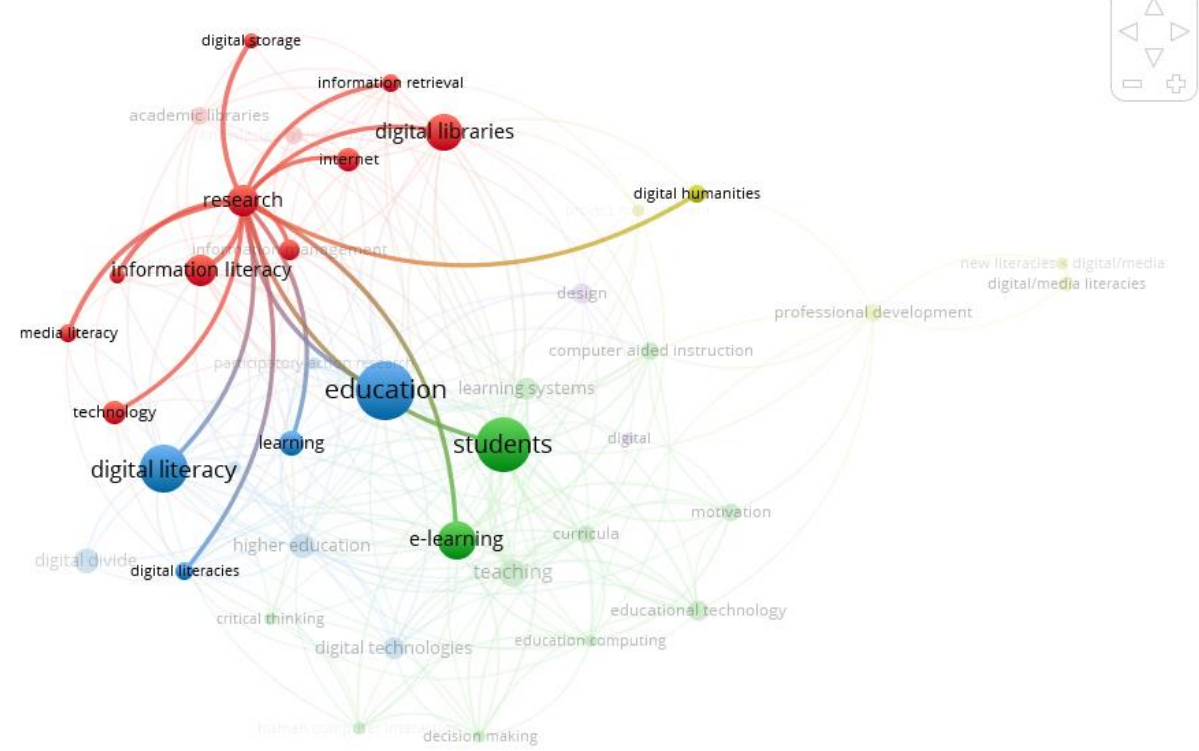

Figure 5. Focus on Item Relationship: Research.

Subsequently, an analysis of the titles and abstracts of the articles was carried out, using the full count mapping method (see Figure 6). The information was filtered to consider only those documents with an item co-occurrence greater than 10 , to select the most significant texts. With this criterion, out of a total of 250 documents, 181 were regarded as relevant. The results showed that the most important terms coming from DRC research could be grouped in three lines of research (LR): 1) the 
DRCs as a part of the triad, teacher-education-learning; 2) the DRCs to make efficient use of libraries and bibliographic resources, and 3) the DRCs as a means to decrease the digital gaps and provide access to computers efficiently.

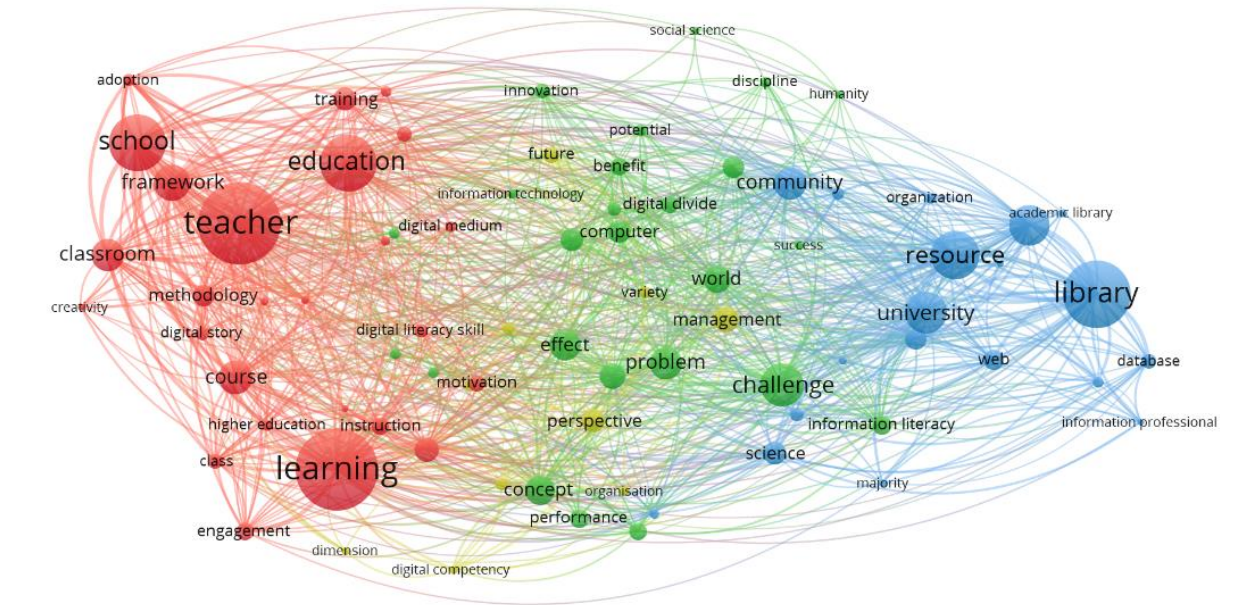

\& vosviewer

Figure 6. Bibliometric map by abstracts.

LR1. Teacher, education, and learning: The red cluster is based on 26 items, among them literacy skill, digital medium, educational technology, and higher education. As with keywords, the term critical thinking arises once again in this analysis, with 27 co-occurrences and a total link strength of 74, which indicates that there exists a strong link between DRCs and the development of skills to manage information critically. Works such as those produced by Albisua et al. [54] and Buckingham [55] support this inference, since they underpin that it is an essential competence linked to questioning and decision making that allows people to act efficiently in innovative knowledge ecosystems. In the same manner, studies by Arévalo et al. [56] confirm that digital abilities and efficient management of technology are transversal objects in the education of researchers.

LR2. Library, resource, university: The second important cluster is shown in blue with 25 cooccurrences. There is a tendency here to link DRCs to skills people have to access resources held in universities' databases and make critical use of retrieved information [57]. There is a great strength with links related to digital divide represented by the lack of skills to perform advanced searches on digital bibliographic media [58], as well as with informational literacy, understood as the technical and experiential skills of researchers to process information with the use of technology [52,59].

LR3. University libraries, digital divide, computers: Colored purple, the highlighted idea is that the study of DRCs is closely linked to the challenges faced by university library users to retrieve academic and scientific information. One of these challenges is again linked to the digital divide and access to computers. Concerning this, Van Ingnen and Matzat [60] mention that discontinuous access to technology translates into inequalities, either to access resources mobilizing the internet or to achieve the development of digital skills. Other co-occurrences in this cluster are linked to the use of databases, resources, and science.

\section{Discussion and conclusions}

Using systematic bibliometric mapping offers the possibility of identifying the landscape of the progress of a scientific field. Its main strength is that it allows descriptions from a great volume of digital documents, and through search refinement processes, delimited information can be obtained on a specific topic in a certain period. Thus, performing these types of studies represents a contribution to the state of knowledge. 
The results of this investigation represent an approximation of the characterization of scientific production of high international impact in the area of research competencies supported by technology. One can observe chronological development, with stagnation until 2014, and a period of growth since 2016, which suggests that the growth will continue to rise and be explored in-depth in the coming years. Equally, we observe a strong trend to link research competencies to digital literacy, the development of critical thinking, digital humanities, and means of access to information in digital libraries.

Concerning territorial evolution, the United States is the country with the largest scientific production and the greatest impact due to the concentration of citations, followed by the United Kingdom; therefore, in a large proportion, the main language is English. On the other hand, scientific production in Spanish is dominated by the journals located in Spain, outshining the contributions coming from Latin America.

As far as the method employed to perform the bibliometric study, note that, even though all the steps suggested by other authors were followed and the information was selected from a trustworthy and internationally prominent database, the search logic may have limitations that come from human refinement. For example, the use of operators, the term inclusion/exclusion criteria, the individual analysis of each article, language barriers, and technical restrictions may affect the search logic and, therefore, the outcomes. Another factor could be that important contributions hosted on high impact national catalogs that are not indexed on Scopus were excluded.

The results that came from the bibliographic maps served as inputs to profile the qualitative analysis. Through interpretation, the analysis showed three contemporary research lines that are linked, namely, teaching and learning, access to bibliographic resources on digital libraries, and the digital divide and computers. Also, dominant items such as literacy skill, digital medium, educational technology, higher education, digital humanities, critical thinking, informational literacy, and digital divide were identified.

As mentioned previously, the limitations of this investigation could result from the selection of Scopus as the sole source of information, and similar studies could be replicated using other databases. Many international impact publications were not considered because they were not in the Scopus index; certainly, there could be important studies on the subject of the development of research competencies as well as researchers who have done outstanding work.

Prospectively, there is now an open invitation to examine the impact of indexed contributions in other databases such as Web of Science, ERIC, SAGE Journals, Google Scholar, or the several other classification systems that exist for high-impact, international and national journals in many different countries. Also, the inclusion of complementary analysis criteria that can be used with the VOSViewer software must be considered, for example, collaboration among authors, individual productions by one author, and citations shared among authors.

Author Contributions: In this research, both authors substantially established and contributed to the approach of this study. C.E.G.R. greatly contributed to the conceptualization, literature review, guidelines for the methodology and review of style and writing, whereas L.D.G.M. greatly contributed to the organization and analysis of the research data. Both authors contributed to the discussion of results.

Funding: This research received no external funding.

Acknowledgments: The authors would like to acknowledge the technical support of Writing Lab, TecLabs, Tecnologico de Monterrey, Mexico, in the production of this work.

Conflicts of Interest: The authors declare no conflict of interest.

\section{Appendix A}

Access link to the database created for the analysis of the literature systematic mapping: https://drive.google.com/file/d/1 RnmdIx1v8MHfXwBnvsG16gzOW5ZQh7h/view?usp=sharing 


\section{References}

1. Buendía, X., Zambrano, C. \& Insuasty, E. Development of Research Skills in Pre-Service Teachers in the Context of the Teaching Practice. Folios. 2018, 47, 179-195. http://www.scielo.org.co/pdf/folios/n47/01234870-folios-47-00179.pdf

2. Estrada, O. Theoretical Systematization of Research Competence. Rev. Elec. Educare. 2014, 18(2) 177-194. https://doi.org/10.15359/ree.18-2.9

3. Murillo, F. \& Perines, H. How non-university teachers perceive educational research. Rev. Complutense Ed. 2017, 28(1), 81-99. https://doi.org/10.5209/rev RCED.2017.v28.n1.48800

4. Perines, H. \& Murillo, F. How to improve educational research? Suggestions from teachers. Rev. Ed. Sup. 2017, 46(181), 89-104. http://dx.doi.org/10.1016/j.resu.2016.11.003

5. Dana, F. \& Yendol, D. The Reflective Educator's Guide To Classroom Research: Learning to teach and teaching to learn through practitioner inquiry. Thousand Oaks: Corwin Press. 2014.

6. Rubio, M., Torrado, M., Quirós, C. \& Valls, R. Self-perception of investigative competences in final-year students of Pedagogy of the University of Barcelona to develop the Final Grade Work. Rev. Complutense Ed. 2018, 29(2), 335-354, http://dx.doi.org/10.5209/RCED.52443

7. Gayol, M., Montenegro, S., Tarrés, M. \& D'Ottavio, A. Competencias investigativas. Su desarrollo en carreras del área de la salud. UNI-PLURI/VERSIDAD. 2008, 8(2), 1-8. https://revistas.udea.edu.co/index.php/unip/article/view/950/823

8. Thongsong, B., Yamtim, V. \& Jai-Areesuthiwa, A. Research competency enhancement process based on knowledge management procedures for developing routine to research of support staff at thaksin university. Kasetsart J. Soc. Sci. 2020, 41(2), 441-448. https://doi.org/10.34044/j.kjss.2020.41.2.15

9. Nakamura, P., Rivero, C. \& Velasco, A. Eveloping research competencies in education students through situated learning. Aula Enc. 2019, 21(1), 182-197. https://doi.org/10.17561/ae.v21i1.10

10. George, C. \& Salado, L. Research competences with ICT in PhD students. Apertura. 2019, 11(1), 40-55. http://dx.doi.org/10.32870/Ap.v11n1

11. Campos, H. \& Ramírez, M. ICT in the educational processes of a Public Research Center. Apertura, 10(1). 2018, 56-70. http://dx.doi.org/10.32870/Ap.v10n1

12. Mas, $\mathrm{O}$. The influence of experience on the research competencies of university professors. Rev. Complutense Ed. 2016, 27(1), 13-34. https://doi.org/10.5209/rev RCED.2016.v27.n1.44706

13. Leonard, \& Wibawa, B. Development of teacher research competency training system in indonesia: A need analysis. Univ. J. Educ. Res. 2020, 8(5), 2064-2070. https://doi.org/10.13189/ujer.2020.080544

14. Albareda, S., Vidal, S., Pujol, M. \& Fernández, M. Holistic approaches to develop sustainability and research competencies in pre-service teacher training. Sustainability. 2018, 10(10) https://doi.org/10.3390/su10103698

15. Anisimova, T., Sabirova, F. \& Shatunova, O. Formation of design and research competencies in future teachers in the framework of STEAM education. Int. J. E. Tech. Lear. 2020, 15(2), 204-217. https://doi.org/10.3991/ijet.v15i02.11537

16. Castañeda, L., Esteve, F., \& Adell, J. Why rethinking teaching competence for the digital world? RED. 2018, 56, 2-20. https://doi.org/10.6018/red/56/6

17. Tourón, J., Martín, D., Navarro, E., Pradas, S., \& Íñigo, V. Construct validation of a questionnaire to measure teachers' digital competence (TDC). Rev. Esp. Ped.. 2018, 76(269), 25-54. https://doi.org/10.22550/REP76-1$\underline{2018-02}$ 
18. Batane, T., \& Ngwako, A. Technology use by pre-service teachers during teaching practice: Are new teachers embracing technology right away in their first teaching experience? Aust. J. Educ. Tech. 2017, 33(1), 58-61. https://doi.org/10.14742/ajet.2299

19. Gudmundsdottir, G. \& Hatlevik, O. Newly qualified teachers' professional digital competence: implications for teacher education. Eur. J. Teach. Educ. 2018, 41(2), 214-231. https://doi.org/10.1080/02619768.2017.1416085

20. Domingo, M., Bosco, A., Carrasco, S \& Sánchez, J. Fostering teacher's digital competence at university: The perception of students and teachers. Rev. Inv. Educ. 2020, 38(1), 167-782. http://dx.doi.org/10.6018/rie.340551

21. Millard, A. Baldassar, L. \& Wildingb, R. The significance of digital citizenship in the well-being of older migrants. Pub. Heal. 2018, 158, 144-148. https://doi.org/10.1016/j.puhe.2018.03.005

22. Davidson, Z. \& Palermo, C. Developing Research Competence in Undergraduate Students through Handson Learning. J. Biom. Edu. 2015, 1,1-9. http://dx.doi.org/10.1155/2015/306380

23. Márquez, A.; Santamaría, D. \& Acosta, R. Validación del perfil de competencias Investigativas para estudiantes de la carrera Licenciatura en Cultura Física. Rev. Lec. Educ. Fís. Dep. 2016, 21(215). https://www.efdeportes.com/efd215/competencias-investigativas-en-cultura-fisica.htm

24. López, E., Vázquez, E. \& Román, P. Analysis and Implications of the Impact of MOOC Movement in the Scientific Community: JCR and Scopus (2010-13). Comunicar. 2015, (44), 73-80. http://dx.doi.org/10.3916/C44-2015-08

25. Pérez, M. \& Vladimirovna, N. The scientific production on social innovation for local development: a bibliometric review. The structure and evolution of the field of scientific domain. Pris. Soc. 2017, 19, 146182. https://revistaprismasocial.es/article/view/1750

26. Petersen, K., Robert F., Shahid, M. \& Mattsson, M. Systematic Mapping Studies in Software Engineering. EASE. 2008, 8, 68-77. https://cutt.ly/OyHGni4

27. García, A. \& Ramírez, M. Systematic Mapping of Scientific Production on Open Innovation (2015-2018): Opportunities for Sustainable Training Environments. Sustainability. 2019, 11, art1781. https://doi.org/10.3390/su11061781

28. Van Eck, J. \& Waltman, L. Citation-based clustering of publications using CitNetExplorer and VOSviewer. Scientometrics. 2017, 111 (2), 1053-1070. http://dx.doi.org/10.1007/s11192-017-2300-7

29. Howard, H., Wood, N. \& Stonebraker, I. Mapping information literacy using the business research competencies. Ref. Serv. Rev. 2018, 46(4), 543-564. https://doi.org/10.1108/RSR-12-2017-0048

30. Matcharashvili, T., Tsveraidze, Z., Sborshchikovi, A. \& Matcharashvili, T. The importance of bibliometric indicators for the analysis of research performance in Georgia. TRAMES, 2014, 18(68). https://doi.org/345356. 10.3176/tr.2014.4.03

31. Abad E. González, M., Luque de la Rosa, A. \& Gallardo, J. Management of the digital economy in higher education: trends and future perspectives. Camp. Virt. 2020, 9(1), 57-68. http://uajournals.com/ojs/index.php/campusvirtuales/article/view/621/396

32. Bornmann, L., Thor, A., Marx, W., \& Schier, H. The application of bibliometrics to research evaluation in the humanities and social sciences: An exploratory study using normalized Google Scholar data for the publications of a research institute. J. Assoc. Inf. Sci. and Tech. 2016, 67 (11), 2778-2789. http://dx.doi.org/10.1002/asi.23627

33. Moreno, A. Estudio bibliométrico de la producción científica en Web of Science: Formación Profesional y blended learning. Píxel-Bit. 2019, 56, 149-168. https://doi.org/10.12795/pixelbit.2019.i56.08 
34. Peirats, J., Marín, D. \& Vidal, M. Bibliometrics applied to gamification as a digital learning strategy. RED. 2019, 60. http://dx.doi.org/10.6018/red/60/05

35. Yang, K., Liu, X. \& Chen, G. Global research trends in robot education in 2009-2019: A bibliometric analisis. Int. J. Inf. Educ. Tech. 2020, 10(6), 476-481. https://doi.org/10.18178/ijiet.2020.10.6.1410

36. Velasco, B., Eiros, J. \& San Román, J. La utilización de los indicadores bibliométricos para evaluar la $\begin{array}{llllll}\text { actividad } \quad \text { investigadora. } & \text { Aula } & \text { 2012, } & 40(2), & \text { 75-84. }\end{array}$ https://www.unioviedo.es/reunido/index.php/AA/issue/viewIssue/1039/145

37. Hallinger, P. \& Chatpinyakoop, C. A Bibliometric Review of Research on Higher Education for Sustainable Development, 1998-2018. Sustainability. 2019, 11, art2401; https://doi.org/10.3390/su11082401

38. Rodríguez A., Trujillo, J. \& Sánchez, J. Impact of scientific productivity on digital competence of future teachers: bibliometric approach on Scopus and Web of Science. Rev. Complutense Educ. 2018, 30(2), 623-646. http://dx.doi.org/10.5209/RCED.58862

39. Price, D. Little Science, big science, and beyond. Nueva York, NY: Columbia University Press. (1986).

40. Ramírez, A., Martínez, K., Aguilar, J. \& Rodríguez, M. The presence of ICT in Revista de la Educación Superior (ANUIES). Rev. Educ. Sup. 2018, 47(187), 133-162. https://doi.org/10.36857/resu.2018.187.422

41. Baker, F. Information Retrieval Based upon Latent Class Analysis. J. ACM (JACM). 1962, 9(4), 512521.https://doi.org/10.1145/321138.321148

42. Kruse, F. \& Thestrup, J. Research libraries' new role in research data management, current trends, and visions in Denmark. LIBER Quart. 2014, 34(4), 310-335. https://doi.org/10.18352/lq.9173

43. Green, J., Yu, S. \& Copeland, D. Measuring critical components of digital literacy and their relationships with learning. Comp. Educ. 2014, 76, 55-69. https://doi.org/10.1016/j.compedu.2014.03.008

44. Green, J. Copeland, D., Deekens, V. \& Yu, S. Beyond knowledge: Examining digital literacy's role in the acquisition of understanding in science. Comp. Educ. 2018, 117, 141-159. https://doi.org/10.1016/j.compedu.2017.10.003

45. Mizrachi, D. Online or print: Which do students prefer? Comm. Comp. Inf. Sci. 2014, 492, 733-742. https://doi.org/10.1007/978-3-319-14136-7 76

46. Maer, M., Mocanu, C., Zamfir, A. \& Georgescu, T. Skill Needs For Early Career Researchers-A Text Mining Approach. Sustainability. 2019, 11(10), art2789. https://doi.org/10.3390/su11102789

47. Kammerer, Y., Brand, S. \& Jarodska, H. The future of learning by searching the web: Mobile, social, and multimodal. Front. Lear. Res. 2018, 6(2), 81-91. https://doi.org/10.14786/flr.v6i2.343

48. Quyyum, D. \& Smith, D. Changing Research Behaviours of University Students with Progression throughout a Course. J. Aust. Lib. Inf. Assoc. 2018, (67)3, 256-277. https://doi.org/10.1080/24750158.2018.1502243

49. Soltovets, Chigisheva \& Dmitrova, A. The role of mentoring in digital literacy development of doctoral students at British universities. Eur. J. Math. Sci. Tech. Educ. 2020, 16(4), em1839. https://doi.org/10.29333/ejmste/117782

50. Pérez, A., García, R.\& Aguaded, I. Dimensions of digital literacy based on five models of development. Cult. Edu. 2019, 31(2), 232-266. https://doi.org/10.1080/11356405.2019.1603274

51. Sánchez, J., Farrán, X., Baiges, E. \& Suárez, C. Critical processing of information on university students from personal learning environments. Educ. Pesq. 2019, 45, e193355. https://doi.org/10.1590/S1678$\underline{4634201945193355}$

52. Given, L. \& Willson, R. Information technology and the humanities scholar: Documenting digital research practices. J. Assoc. Inf. Sci. Tech. 2018, 69(6), 807-819. https://doi.org/10.1002/asi.24008 
53. Tsatsou, P. Literacy and training in digital research: Researchers' views in five social science and humanities disciplines. New Med. Soc. 2018, 20(3), 1240-1259. https://doi.org/10.1177/1461444816688274

54. Albisua, M., Ruíz, M., Nogueira, D., Turnes, S. \& Carrasco, L. Critical Thinking from the Perspective of University Teachers. Est. Ped. 2018, 44(1), 89-113. https://doi.org/10.4067/S0718-07052018000100089

55. Buckingham, D. Teaching media in a 'post-truth' age: fake news, media bias and the challenge for media/digital literacy education. Cult. Educ. 2019, 31(2), 213-231. https://doi.org/10.1080/11356405.2019.1603814

56. Arévalo, R., Del Prado, R. \& Ramírez, R. Institutional education of communication researchers and media literacy. The case of the PhD in communication research. Rev. Lat. Com. Soc. 2016, 71, 800-817. https://doi.org/10.4185/RLCS-2016-1121en

57. Hartsell, A., Lawton, K., \& Roear, H. Seven librarians and one big undertaking: creating a digital project from start to finish. J. Elec. Res. Libr. 2020, 32(1), 19-28. https://doi.org/10.1080/1941126X.2019.1709730

58. Arshad, A. \& Ameen, K. Academic scientists' scholarly use of information resources in the digital environment: Perceptions and barriers. Glob. Know. Mem. Comm. 2018, 67(6), 467-483. https://doi.org/10.1108/GKMC-05-2018-0044

59. Avalos, C. \& Sevilllano, M. The development of research competences through the Lean Startup methodology in students training at the State Distance University in Costa Rica. Educ. S. XXI. 2018, (36)3, 417-442. http://dx.doi.org/10.6018/j/350071

60. Van Ingen, E. \& Matazat, U. Inequality in mobilizing online help after a negative life event: the role of education, digital skills, and capital-enhancing Internet use. Information, Comm. Soc. 2018, 21(4), 481-498. https://doi.org/10.1080/1369118X.2017.1293708 